white, white on blue (or vice versa) but don't include green, brown, red, or orange in graphs please! Take this to your committee and make them read it every year, and include this in their instructions to contributors. Am I seeing red or just feeling blue ?"

Critical comments on matters such as behaviour of participants, such as smoking, excessive noise, speakers' deliveries, chairmanship of sessions, programme and/or organisational details. This type of message is not necessarily couched in acrimonious language-indeed, cartoons have been used to illustrate such points.

Examples: "You can't have 'three moities' Two only allowed. 'La moitie' means half."

"Please don't use dual projection to cram more information into the available time! I'm overloaded already."

General comments, insights, related experience, or humorous commentary and appreciative messages.

The messages used as examples were extracted from conference bulletins.
Some might ask-why have a bulletin at all ? Why not just have a notice board? There are sound reasons for providing a bulletin. Some people dislike constantly monitoring notice boards at a central site and others cannot remember to do so. At a large conference crowds may gather about bulletin boards and obstruct them. Most important, perhaps, is the attachment most of us feel for the daily newspaper, enhanced, one hopes, in the case of a free, well produced conference "extra." Participant messaging overcomes the problems facing conference organisers of what to put in a daily bulletin; they often feel the need for some personalising influence in the meeting but lack material of sufficient interest to make a daily publication worth while. Messaging adds a new dimension of interest to a meeting. If the value of meetings is perceived to have some relationship to one's own input, as we believe it is, the messaging system offers the opportunity for a few more participants to go home satisfied.

\section{Reference}

1 Judge AJN. Participant interaction messaging-improving the conference process. Transnational Associations 1980;1:27-35.

\title{
An avoidable recurrence of cri du chat syndrome in the next generation
}

\author{
J BURN, M BARAITSER, L J BUTLER
}

Genetic counselling plays an important part in preventing handicap. Much attention is devoted to the identification of people at risk, especially for late onset autosomal dominant disorders, $\mathrm{X}$ linked diseases, and familial chromosomal translocations. In such cases it is common for family members to be unaware that they face substantial risks of having a handicapped child.

When carriers of balanced reciprocal translocations are ascertained through the birth of a child with unbalanced chromosomes the risk of a second child being malformed is close to 1 in $5 .^{1}$ Thus it is important to offer prenatal screening in all subsequent pregnancies. Considerable efforts are made to reach relatives at risk, but it is difficult to ensure that the necessary information is available to the next generation. Current practice is to tell the parents of the risk to offspring of their "carrier" children, and to suggest that they are told of the risk in late adolescence, when a further meeting with a genetic counsellor may be

\footnotetext{
The Hospital for Sick Children, Great Ormond Street, London WC1N 3JH

J BURN, MB, MRCP, senior registrar in clinical genetics M BARAITSER, MB, FRCP, consultant clinical geneticist

Queen Elizabeth Hospital for Children, Hackney Road, Bethnal Green, London E2 8PS

L J BUTLER, BSC, director of cytogenetics

Correspondence to: $\operatorname{Dr} \mathrm{M}$ Baraitser.
}

\section{Genetic registers may be necessary to reduce avoidable genetic abnormalities}

arranged. Such advice is supported by a letter to the general practitioner. We report a failure of this line of communication and discuss the implications.

\section{4}

The original proband was born on 28 September 1964, the seventh child of the family. He was severely mentally and physically retarded and at the age of 3 years blood was collected for chromosome examination. This showed a deletion of the short arm of a B group chromosome, resulting in the cri du chat syndrome. The family was referred for genetic advice. The couple had lost their three daughters in the first year of life; all three had failed to thrive and the causes of death had been gastroenteritis, pneumonia, and convulsions respectively. There were three healthy sons, all of whom, together with the mother, carried the same deleted B group chromosome and were presumed to be carriers of a balanced chromosomal translocation. The techniques available at the time did not permit an identification of the other chromosomes affected in the interchange. 
In accordance with practice then and now the parents were seen and the whole situation was explained. A letter sent to the general practitioner pointed out that the boys were carriers of a balanced translocation and stated that "it would be wise for them to have advice when they (are) aged 19 or so, and thinking of getting married." In 1968 the boys were 14, 10, and 3 years of age. The proband made his last visit to hospital in June 1970 and died shortly thereafter.

\section{2}

The family turned up again in 1982 at the assessment centre of another hospital. On 6 October 1980 the wife of one of the brothers of the original proband (arrowed in figure) had given birth to a daughter, III4. The child was found subsequently to be severely retarded in mental and motor development, and

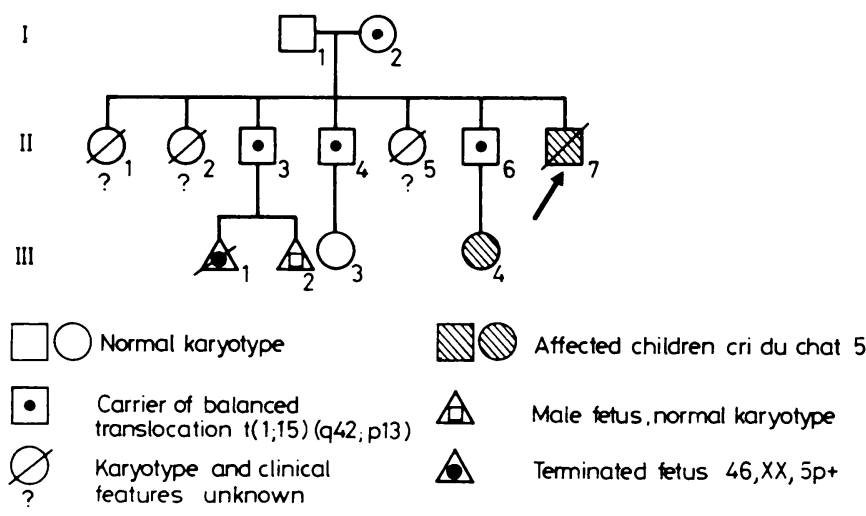

Pedigree of family with chromosome abnormality causing cri du chat syndrome.

this, together with an unusual facial appearance, prompted an examination of her chromosomes in November 1981. Absence of the short arm of a chromosome 5 confirmed that, like her now deceased paternal uncle she had the cri du chat syndrome: $5 \mathrm{p}$-. The members of the family were re-examined and the carrier status of the brothers re-established and made known to them. Using banding techniques, we could now show that there had been a reciprocal translocation between the long arm of a chromosome 1 and the short arm of a chromosome 5, with break points at $\mathrm{q} 42$ and $\mathrm{p} 13$ respectively.

By this time the wife of II3 was 15 weeks pregnant. It was explained to the parents that they faced a high risk of a chromosomally abnormal child. The mother elected to have an amniocentesis, which showed the alternative unbalanced karyotype in the fetus; trisomy for the short arm of chromosome 5. The pregnancy was terminated and the fetus had several congenital malformations consistant with the $5 p$ - syndrome. Investigation of her current pregnancy has shown a normal male karyotype $46 \mathrm{XY}$.

\section{Comment}

After a long discussion the three families now understand the basis of their problem, but are angry and embittered at the failure of the medical system to warn them of the danger they faced. This criticism was difficult to answer. It would have been simple to lay the blame on their parents for failing to pass on the necessary information, but after meeting the mother it was clear that whereas she remembered the visit to the hospital 15 years earlier, she had found it impossible both emotionally and intellectually to inform her children adequately.

What lesson may be learnt from these families who failed to receive the information to which they were entitled? In theory the notes of their general practitioners contained a reference to the warning letter sent in 1968. In practice it is not difficult to see how this mechanism of communication failed, especially when there may have been several changes of practitioner.

In some units the counsellor will write to the parents in the hope that they will one day remember to show the letter to their children. It has yet to be shown that this hope is any less forlorn than the hope that parents will advise their children verbally. The only alternative is some mechanism of long term follow up, which becomes, in effect, a genetic register.

There has been much discussion on the values and dangers of genetic registers. A Clinical Genetics Society Working Party ${ }^{2}$ has concluded that registers are most likely to be effective and to remain confidential if they are organised in the region and based in clinical genetics units. A few regions have made progress, but in most there has been no attempt to establish such a system.

There are lessons to be learnt from the Medical Research Council/Department of Health and Social Security phenylketonuria register. ${ }^{3}$ The hospital consultant, family doctor, or community physician who is responsible for a female patient known to have phenylketonuria is contacted when his patient reaches the age of 14 . The primary purpose is to permit a prospective study of pregnancies in these young women. The contact has the effect of drawing the physician's attention to the need for review so that the girl may be advised to return to the low phenylalanine diet before a planned conception. Some 250 women are being followed (Dr Isabel Smith, personal communication). It is hoped that this register will help to prevent the birth of severely damaged children.

Funding is the major problem, since permanent staff are essential, as is a dedicated microcomputer. In view of the economic climate and the history of preventive health measures it is likely that although many genetic handicaps are avoidable, it will be some time before they are avoided.

$\mathrm{J}$ Burn is supported by the Medical Research Council, project grant number G8203878.

\section{References}

1 Boué A. European Collaborative Study on Structural Chromosome Anomalies in Prenatal diagnosis. Abstracts of proceedings of 6th International Congress of Human Genetics, ferusalem. 1981.

2 Emery AEH, Brough C, Crawfurd M, Harper P, Harris R, Oakshott G. A report on genetic registers. F Med Genetics $1978 ; 15: 435-42$.

${ }^{3}$ MRC DHSS Phenylketonuria Register. Newsletter No 8, 1982:8.

(Accepted 10 fune 1983)

A 34 year old woman develops urticaria and excessive nasal secretion after sexual intercourse. What treatment is advised?

A few cases of urticaria, nasal congestion, and even more generalised symptoms of anaphylaxis after sexual intercourse, have been reported. ${ }^{12}$ Thse symptoms are attributable to an IgE mediated allergic reaction to seminal plasma. Laboratory evidence suggests that the reaction occurs after vasectomy and that even a change of partner would not eliminate the symptoms. The problem is therefore quite different from the thorny problem of whether allergy to spermatozoa can cause infertility. If the symptoms are not prevented by the use of a condom you might have to consider an alternative diagnosis of cholinergic urticaria. This is normally provoked by exertion or excitement and can be associated with respiratory symptoms. ${ }^{3}$ With either diagnosis antihistamines could be expected to provide only partial relief. $-\mathrm{R} H$ CHAMPION, consultant dermatologist, Cambridge.

Levine BB, Siraganian RP, Schenkein I. Allergy to human seminal plasma. $N$ Engl 7. Med 1973;288:894-6.

Schulz KH, Schirren C, Kueppers F. Allergy to seminal fluid. N Engl F Med 1974;

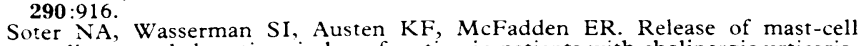
mediators and alterations in lung function in patients with cholinergic urticaria. $N$ Engl f Med 1980;302:664-8. 